\title{
Introducing a New Journal at the Interface of Technology, Psychology, Medicine, Policy, Health Administration, and Behavioral Science
}

\author{
Donald M. Hilty ${ }^{1}$
}

Published online: 14 August 2017

(C) Springer International Publishing 2017

\begin{abstract}
"We need approaches to the solutions that aren't just arithmetic and additive, but are in some sense logarithmic. This will require us to reach across historic boundaries and unlock the potential of collaboration across the usual disciplines." Jeffrey S. Flier, MD - Dean of the Faculty of Medicine, Harvard's First Forum on Health Care Innovation, July, 2013
\end{abstract}

Dr. Flier's remarks above reflect the imperatives of the Health Care Innovation Forum which were:

1. Making value the central objective

2. Promoting novel approaches to process improvement

3. Making consumerism really work

4. Decentralizing approaches to problem solving

5. Integrating new approaches into established organizations

It is in this spirit that the Journal of Technology in Behavioral Science (JTiBS) has been conceived, initiated by its sponsoring organization, the Coalition for Technology in Behavioral Science (CTiBS). CTiBS, organized as a non-profit in 2014 by behavioral leaders, including Founding President, Marlene M. Maheu, Ph.D., focuses on three priorities: (1) the development of competencies for behavioral professionals using technologies, (2) the need to organize human, administrative, clinical, research, and other fields' resources, (3) to provide an inter-professional, international journal to support the scientific development of

Donald M. Hilty

donh032612@gmail.com

1 Kaweah Delta Health Care District and University of Southern California, Los Angeles, CA, USA technology for psychiatry, psychology, social work, counseling, marriage and family therapy, addictions, nursing practice, behavior analysis, health coaching, and other professions. Prior to CTiBS's founding, members had worked together for over five years to expand awareness of its priorities by US national professional associations. This work has led to the launch of this first issue - actualizing the vision and mission of CTiBS through JTiBS.

This Journal has been designed to help professionals meet the increasingly complex needs of those seeking mental health care. In the current technological environment, there is a wide audience for this information. As such, JTiBS aims to address the needs of a range of professionals, including clinicians, researchers, teachers/learners, administrators, healthcare leaders, and policy makers. High-quality articles focusing on the locus of technology, behavioral science, and healthcare will advance knowledge and skills in mental health, cognitive science, psychiatry, psychology, psychobiology and other fields. The journal also aims to be informed by other allied fields such as economics, public health, population health, epidemiology, biostatistics, history, and informatics. To keep up with the increasingly complex needs of clinicians, clients/ patients, learners, researchers of the present and the future, we need innovation by technology, models of service delivery, and interdisciplinary teamwork to have logarithmic and/or exponential impact.

\section{Aims and Scope}

JTiBS explores the intersection of human behavior, use of technology, and healthcare. It considers the social, psychological, cultural, biological, and other medical contexts of behavior. JTiBS is an international forum and repository for the 
exchange of ideas between professionals engaged in science, practice, policy, and education. It promotes interprofessional scholarship and interdisciplinary collaboration, which transcend geographical, cultural, disciplinary, and methodological boundaries. JTiBS bridges the separate but overlapping scientific literature and evidence-bases (e.g., for behavioral healthcare itself, JTiBS spans behavioral analysis, counseling, marriage, and family therapy, psychiatry, psychology, social work, and substance use). Contributions from cognitive science, psychiatry, psychology, psychobiology, and fields in/ associated with technology.

JTiBS will feature original research, systematic reviews, and studies of evidence-based practice. It also welcomes theoretical articles, position papers, guidelines, and editorials on behavioral health, telemental health, mHealth, technology, education, eLearning, innovation, and policy. To achieve its goals, JTiBS embraces a variety of methodologies (e.g., surveys and questionnaires, randomized controlled trials, direct observation, descriptive methods, laboratory and field experiments, economic analyses, conference proceedings, project and program profiles, ethnography, evaluation, and resource listings).

Our goal is to provide a meeting place, inspire new ideas, and generate discussion among our many readers. Columns, editorials/commentaries, and letters help in this process. The five continuing features planned so far are:

- Research in Technology and Behavioral Sciences

- Technological Innovation

- Tele-competency, Evaluation and Outcomes

- New Developments and Resources in Technology for Behavioral Science

- Law, Ethics, and Policy

We look forward to a robust and inclusive participation of the full range ot relevants disciplines. 